\title{
Does the Hybridizing of Intercultural Potential Facilitate Efficient Technology Transfer? An Empirical Study on Japanese Manufacturing Subsidiaries in Vietnam
}

\author{
Nguyen Thi Duc Nguyen ${ }^{1} \&$ Atsushi Aoyama ${ }^{1}$ \\ ${ }^{1}$ Graduate School of Technology Management, Ritsumeikan University, Kusatsu, Japan \\ Correspondence: Nguyen Thi Duc Nguyen, Graduate School of Technology Management, Ritsumeikan \\ University, 525-8577 Noji-higashi 1-1-1, Kusatsu, Shiga, Japan. Tel: 81-803-831-3168. E-mail: \\ ntducnguyen@yahoo.co.jp
}

Received: May 3, 2012 Accepted: June 4, 2012 Online Published: August 17, 2012

doi:10.5539/ass.v8n11p26

URL: http://dx.doi.org/10.5539/ass.v8n11p26

\begin{abstract}
This study investigates the management similarities, management compatibilities, and practical approaches synergizing the intercultural potential to facilitate efficient technology transfer. It utilizes Hofstede's cultural dimensions, with Abo's theoretical management system and Adler's intercultural synergy framework, to conduct qualitative data collection through in-depth interviews, focus groups, and observations on at 13 Japanese manufacturing subsidiaries in Vietnam. The study finds that five essential factors occurring in technology transfer-frequent interaction, training, team-based work, quality practice, and managerial commitment-can properly integrate the similarities and complementary potential of Vietnamese and Japanese management practice. This study proposes a working framework focusing on directions of determining each culture's combinable management perspectives, ways of synergizing them, and the possibilities for intercultural synergies to promote technology transfer performance in culturally different contexts. It is suggested that hybrid managerial practices represent not only convergent management styles but also intellectual strategies for exploiting home and host advantages in efficient technology transfer, thus creating the critical foundation of an organizational culture.
\end{abstract}

Keywords: technology transfer, intercultural synergy, hybrid managerial practices, Japanese company, Vietnam.

\section{Introduction}

International economies continue to grow, countries are uniting, and the global culture is increasingly becoming a center of the promotion of human factors for long-term cooperation and competitive advantage. The important role of culture in international management is clear, though foreign companies often fail to systematically and efficiently address cultural issues (Adler \& Gundersen, 2008).

At the same time, the research on cross-cultural technology transfer has undergone significant change. Previous research in this field has exclusively discussed the various characteristics relating to international technology transfer (e.g., Pak \& Park, 2004; Le \& Evangelista, 2007; Sazali, Raduan, Jegak, \& Haslinda, 2009), emphasizing the importance of national culture in the knowledge transfer and technology transfer processes within cross-cultural business contexts (e.g., Davenport \& Prusak, 2000; Holden, 2002). It has become increasingly necessary to address the practical need to seek problem-solving approaches originating from cultural origins and the link between efficient technology transfer performance and national culture. Accordingly, the emerging issues - how to deal with cultural challenges in positive ways to more efficiently achieve technology transfer performance and how to turn cultural potential into technology transfer advantages - have not yet been systematically addressed. This has revealed that the notion of "cultural fit", involving a series of optimal analysis of inter-cultural compromises, could be considered relevant for the current problems.

Interviews conducted during a pilot study that explored the positive ways of dealing with the impact of cultural differences on technology transfer implementation for Japanese subsidiaries in Vietnam (Nguyen, Takanashi, \& Aoyama, 2012) were factors leading us to propose that intercultural potential should be highlighted and utilized. Although the Japanese and Vietnamese management perspectives on technology transfer practices have obvious differences, a few similarities and compatibilities prevail. Japanese and Vietnamese cultures have been fairly 
similar since the $17^{\text {th }}$ and $18^{\text {th }}$ centuries, as both were wet-rice agricultural countries with cultural values based on Confucianism and Buddhism (Tran, 1999; Pham, Vu, \& Tran, 2001).

On the practical level, Japanese subsidiaries in Vietnam are facing the need to increase wages because of inflation in the Vietnamese market and higher productivity. Technology transfer involves dynamic work-including human factors and fostering technology-oriented minds - not simply the static transfer of packages of technical matter (Yamashita, 1991). Therefore, the pressure for technology transfer in Vietnam emphasizes the need for dynamic technology transfer, including continuous improvement, firm productivity, the knowledge fundamentals for innovation, and long-term competitive advantages.

In order to respond to these issues, this study exploits the context of Japanese manufacturing subsidiaries in Vietnam for conducting the qualitative data collection to explore the hybrid solutions from management perspectives that implement synergistic energy for potential advantages of each culture to facilitate international technology transfer performance. Indeed, this approach demonstrates the strength to exploratory research, effectively uncovers what people do, know, think, and feel by observing, interviewing, and analyzing documents (Patton, 1990; Goulding, 2002). It develops thorough and comprehensive descriptions of the phenomenon under research, interconnects research concepts, and helps others understand the transparency of the study (Dey, 1993).

Accordingly, this paper considers technology transfer as the complex process of transferring technological knowledge, information, and know-how across organizational border from developed to less technologically developed countries, through which the technology recipients acquire, absorb, and apply new knowledge to reach production and management execution conditions equal to those of the originating economic entities (Derakhsahani, 1984; Williams \& Gibson, 1990; Yamashita, 1991; Bozeman, 2000; Ando, Kawashima, \& Kan, 2005; Sazali \& Raduan, 2011). This study's notion of technology transfer efficiency is based on Mansfield et al. (1982) and Lin (2007) as well as on interviews with Japanese and Vietnamese managers engaged in acquiring technological knowledge from partners, enhancing knowledge application, and improving innovative capacities to provide process and product quality.

The paper is structured as follows. After a concise introduction of the issues, the prominent research on cross-cultural technology transfer and the extended literature on hybridization in the broad cross-cultural management field are briefly discussed in Section 2. The three theoretical foundations underlying this study-Hofstede's (2010) national culture dimensions, Abo's (1994) management practicing systems, and Adler's (2008) intercultural synergy framework - are described in Section 3. The hypotheses of research design, the qualitative data collection approach using multiple specific methods (in-depth interviews, focus groups, and observations), and analytical framework are presented in Section 4. A line-by-line analysis of the similarities and compatibilities between Vietnamese and Japanese management perspectives on efficient cross-cultural technology transfer, based on the national culture of each country, is presented in Section 5. The formation and advantages of hybrid solutions for efficient technology transfer performance is analyzed in Section 6. On the above analyzing vein, Section 7 proposes a systematic framework providing an insightful view into: (1) how to determine each culture's combinable management perspectives; (2) how hybrid solutions turn the potential advantages of both national cultures into synthetic energy to achieve an efficient technology transfer performance while simultaneously reducing the negative impact of cultural differences. Finally, a conclusion and points for further research are proposed in Section 8.

\section{Relevant Research on Cross-Cultural Technology Transfer}

This study constitutes an intersection of research fields concerning cross-cultural technology transfer and the extended literature of hybridization in the broad field of cross-cultural management. Following the approach of Creswell (2009), the current literature can be summarized as follows.

\subsection{Cross-Cultural Technology Transfer}

Within the research on cross-cultural technology transfer, much quantitative research has investigated the factors inhibiting and facilitating knowledge and technology transfer, but these works have covered only a few dimensions, such as the characteristics of the knowledge, its suppliers and recipients, and their relationships (e.g., Rebentisch \& Ferretti, 1995; Pak \& Park, 2004; Le \& Evangelista, 2007; Sazali, Raduan, Jegak, \& Haslinda, 2009). Some research has indicated the importance of national culture in the cross-cultural knowledge transfer process (e.g., Simonin, 1999; Holden, 2002; Pauleen, Wu, \& Dexter, 2007). Others have pointed out that cultural difference and distance are the key obstacles and are the roots of cultural conflicts and misunderstandings in inter-firm knowledge and technology transfer (e.g., Lyles \& Salk, 1996; Mowery, Oxley, \& Silverman, 1996; Lin \& Berg, 2001, Le \& Evangelista, 2007). However, relatively few exploratory studies have suggested theoretical frameworks for explaining how the differences in national culture affect knowledge transfer using 
Hofstede's culture dimensions (e.g., Bhagat, Kedia, Harveston \& Triandis, 2002; Lucas, 2006, Chen, Sun \& McQueen, 2010). Moreover, little research has investigated how national cultural difference negatively impacts the technology transfer performance of joint international ventures (e.g., Lin \& Berg, 2001; Nguyen, Takanashi, \& Aoyama, 2012).

Briefly, the prior research to date on cross-cultural technology transfer, particularly emphasizing the effects of cultural difference on international technology transfer has not yet been holistically achieved. It has been observed that not only the negative influence of cultural difference on technology transfer has not solved adequately, but also the positive aspect of cultural difference has been lacked. This prevails the potential worthy of further exploring research. Given this background, the notion of "cultural fit" or "cultural synergy", involving a series of analysis of inter-cultural compromises, defined by e.g., Adler \& Gundersen (2008); Schlunze, Hyttel-Srensen, \& Ji (2011), could be considered the optimally strategic solution for the current problems.

\subsection{Hybridization Notion in Cross-Cultural Management}

A review of the extended literature on the cross-cultural management of hybridization reveals that transnational companies face many intercultural challenges and opportunities and that the unity of host and home management practices still prevails. Some of the research utilizing hybridizing notion has investigated on various approaches such as developing a hybrid management structure to create intercultural synergy (e.g., Abo, 1994; Adler \& Gundersen, 2008; Fuller, 2009; Schlunze, Hyttel-Srensen, \& Ji, 2011), matching corporate cultures in joint ventures and mergers (e.g., Tsang, 1998; Ross, 1999), assessing the "fit" between a country's culture and a generic strategy (e.g., Ross, 1999), recognizing the new dimensions of corporate strategy (e.g., Buckley \& Casson, 1998). Chiefly, even though hybridization perspective contributed to cross-cultural management field, it has not yet reached its potential in the cross-cultural technology transfer field.

In short, in a cross-cultural context, the technology transfer process becomes more complex and difficult and involves several aspects of the synthetic view that previous research has lacked both theoretically and empirically. This study serves to integrate the light of hybridizing perspective on cross-cultural management into the cross-cultural technology transfer field, to explore some of the important issues concerning the effects of cultural difference on international technology transfer that the research has yet to sufficiently conceptualize: -how to determine the combinable management perspectives based on each culture, how to synergize them, and why intercultural synergizing can be converted into advantages that efficiently promote technology transfer performance in the context of cultural difference.

\section{Theoretical Background}

\subsection{Hoftede's National Culture}

The concepts of social culture and nation have recently become interesting research themes in cross-cultural business management. Most of the research on cross-cultural issues has focused on cross-national matters, with very few operational definitions of culture (Nasif, Al-Daeaj, Ebrahimi, \& Thibudeaux, 1991; Leung, Bhagat, Buchan, Erez, \& Gibson, 2011). Among these, Hofstede's research is the most representative of the national culture dimensions of work-related cultural value. Although subject to some criticism, Hofstede's work has been used in subsequent studies on cross-cultural management because of its rigorous design, systematic collection, coherent theory, and the relative accuracy of its cultural dimensions (Michael \& College, 1997; Jones \& Alony, 2007; Adler \& Gundersen, 2008; Schlunze, Hyttel-Srensen, \& Ji, 2011).

This study utilizes five of Hofstede's dimensions as a fundamental reference point from which we explore our research questions and group and classify the similarities and compatibilities between the management practices of each country through a national culture "lens." Because they represent highly significant differences in the behaviors and attitudes of the employees and managers of each country (Adler \& Gundersen, 2008), the remaining dimensions are beyond our scope. (1) "Individualism" describes personal relationships, teamwork skills, individual success relative to that of colleagues, the importance of keeping up harmony and saving face, loyalty, and one's sense of duty towards one's work community, superiors, and subordinates. (2) "Power distance" refers to the significance of status differences, the acceptance of the leader's authority, the necessity for guidance and leadership, the values attached to age, and the methods of presenting feedback. (3) "Masculinity" refers to the valuing of achievement, confidence, material wealth, and personal relations, dividing work from free time, defining the quality of working life, the importance of work for an individual, and the expectations and methods of promotion. (4) "Uncertainty avoidance" refers to the sense of timing and punctuality, planning, reactions to changes of plan and rule breaking, ways of expressing emotion in public, the acceptance of different opinions and people, and the necessity for rules, models, standards, and rituals in the work environment. (5) "Long-term orientation" describes how much society values long-term strategies relating 
to setting objectives, vision, and timing the planning of tasks and goals.

\subsection{Abo's Management Practicing System}

Among the works using the management geography approach, the theoretical framework introduced by Abo (1994) presents one of the most valuable to an understanding of the execution of Japanese management practices at hybrid factories overseas. Seven categories need to be understood. (1) "Work organization and administration" refers to job classification, the wage system, job rotation, education and training for engineers and factory workers, and the promotion of first-line supervisors. (2) "Production control" refers to quality control, maintenance, operating management, and production equipment. (3) "Procurement" refers to local content, relations with suppliers, and procurement methods. (4) "Group consciousness" refers to small group activities, information sharing, and the sense of unity. (5) "Labor relations" refers to hiring policy, job security, labor unions, and grievance procedures. (6) "Parent-subsidiary relations" refers to the ratio of Japanese expatriates, the delegation of authority, and the managerial positions of Japanese and local partners. (7) "Community relations" refers to participation in local economic organizations, donations and volunteer activities on behalf of local communities, and competition with local companies.

This study uses Abo's framework, mainly as it relates to internal work organization and administration - job classification, training and education, quality control, hiring policy, group consciousness, and labor relations - to verify the convergence of the data on hybrid managerial practices collected through empirical study.

\subsection{Adler's Intercultural Synergy}

Within cross-cultural management research, the intercultural synergy framework of Adler (2008) is one of the best references concerning the cultural hybridization structure. Indeed, cultural synergy, as an approach to managing the impact of cultural diversity, involves a new way of thinking in its processing of organizational strategic activities and creating optimal forms of management and organization that transcend the distinctiveness of the originating culture (Adler \& Gundersen, 2008). The process of developing culturally synergistic solutions involves three steps: describing the situation from each culture's perspective, culturally interpreting the situation, and developing new, culturally creative solutions. The intercultural synergistic strategies present five basic options-cultural dominance, cultural accommodation, cultural compromise, cultural avoidance, and cultural synergy - that can be flexibly applied to multicultural situations.

Intercultural synergy has been well integrated into various research fields, e.g., on cross-border mergers and acquisitions (Ran, 2008), corporate cultures in joint ventures and mergers (Tsang, 1998; Ross, 1999), international human resource management (Schlunze, Hyttel-Srensen, \& Ji, 2011), and the new dimensions of corporate strategy (Buckley \& Casson, 1998). However, it has not yet reached its potential in the cross-cultural technology transfer field. This study takes advantage of Adler's framework, coupled with Abo's framework, to analytically generalize and examine the coherence of the data collected from Hofstede's framework.

\section{Research Framework}

\subsection{Hypotheses of Research Design}

National culture dimensions are used as the supporting foundation for establishing the empirical inquiry framework guiding the interviews and discussions at Japanese subsidiaries in Vietnam (see Figure 1). Based on this, the semi-structured questions were designed to investigate three core research questions:

Research question 1: What kinds of similarities and compatibilities or combinable potential between Japanese and Vietnamese management styles, based on the national culture of each country, have Japanese subsidiaries in Vietnam utilized to facilitate the technology transfer process?

Research question 2: How have Japanese subsidiaries exploited the above similarities and combinable potential in management perspectives and behavior and converted them into advantages for efficient technology transfer?

Research question 3: Why can the synergizing of cultural potential promote cross-cultural technology transfer performance?

\subsection{Analytical Framework}

\subsubsection{Sampling Criteria}

A purposeful sampling was used to select 13 Japanese manufacturing subsidiaries in Vietnam for this study. These companies are typical Japanese companies in the mechanical manufacturing industries, located in South Vietnamese tech parks. The manufacturing concerns produce equipment for asphalt road-building, butt-welding fittings used in various infrastructural capacities, aluminum extrusion dies, stamping dies, internal components for hydraulic equipment, precision parts, steel ball welding, plastic mold segments, and multidisc torque converters for cars. 


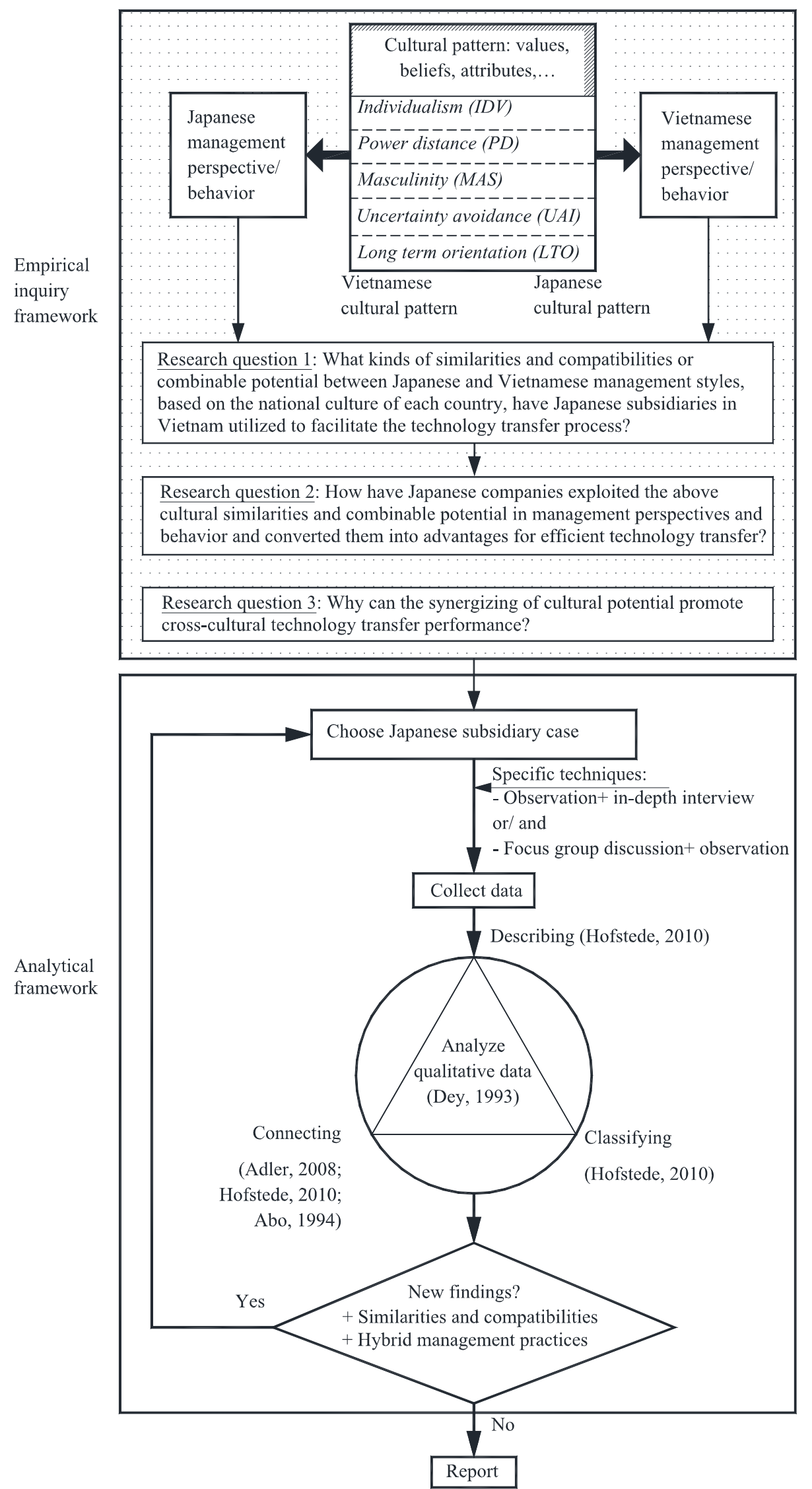

Figure 1. Research framework 


\subsubsection{Empirical Inquiry Approach}

This study followed an empirical inquiry approach, integrating multiple specific methods-in-depth interviews, group discussions, and observations - to investigate the contemporary phenomenon of cross-cultural technology transfer within the contexts of Japanese subsidiaries in Vietnam. This approach provided an insider's view of the descriptive, narrative phenomena and contexts otherwise not clearly evident (Goulding, 2002; Yin, 2009; Blaxter, Hughes, \& Tight, 2010).

First, three pilot studies using in-depth interviews of an average of 3.5 hours in length were conducted to access a rich source of first-hand knowledge, verify the research method, confirm that the questions could meet the research objectives, revise ambiguous questions, and improve the techniques for the later official in-depth interviews. Then, the eight official in-depth interviews (two with senior Japanese managers and six with Vietnamese production managers) and five focus group discussions were held. The small focus group discussions (with from three to six people) occurred at the work locations during the middle stages of the research and at neutral locations during the final stages. This method created an environment that was comfortable and conducive to discussion and argument, allowing an observation of the interactions of many participants, stimulating new ideas, and providing information about subconscious behavior (Hedges, 1985; Goulding, 2002). The direct observation technique was added to the interviews and group discussions in order to gain in-depth information from subjects' actions, especially in cases where subjects had not expressed their feelings on their cross cultural technology transfer experience meaningfully. Complementary techniques were also used in the interviews, such as introductory, probing, direct and indirect, and interpretive questions as well as explanations of unclear issues.

Seven senior Japanese managers and twenty three Vietnamese engineering and production managers at several departments in thirteen Japanese subsidiaries took part in the in-depth interviews and focus group discussions. They were around 45 years old, with an average of 11 years of experience with international technology transfer. The average length of the in-depth interviews was 2 hours and 3.5 for the focus group discussions.

\subsubsection{Data Analysis}

The collected data were compiled by taking extensive notes onsite and rewriting the notes later the same day. Techniques and progressive procedures-describing, classifying, and connecting-using the circular qualitative analysis process of Dey (1993) were applied to interpret the data. Specifically, the collected data were: (1) initially described, classified, and conceptually ordered according to Hofstede's dimensions; and then (2) constantly close-in compared, analytically generalized, and checked for coherency with Adler's intercultural synergy framework, Hofstede's cultural theory, and with reference to Abo's management practicing system framework (see Figure 1). The number of companies was increased gradually as the findings grew, obtaining stability after five months of intensive research investigation.

\section{Analytical Result-1: The Management Similarities/Compatibilities with National Culture Insight}

With respect to the results of the discussions and interviews with the managers at the Japanese manufacturing subsidiaries, this section presents the discovered similarities and compatibilities between Vietnamese and Japanese management perspectives and behaviors that were stressed as potential advantages for promoting and facilitating an efficient technology transfer performance. They are conceptually analyzed through Hofstede's cultural dimensions-collectivism/individualism, power distance, masculinity, uncertainty avoidance, and long-term orientation-, particularly in terms of each national culture's fundamental understanding of human nature.

\subsection{Collectivism/Individualism (IDV)}

According to Hofstede, Hofstede, \& Minkov (2010), Japan and Vietnam are both collectivistic societies that strongly tie people together within their communities. Our interviews and discussions revealed the interesting aspects below.

\subsubsection{Team Spirit}

The Vietnamese community's perspective on maintaining various modes of cooperation and strong solidarity was stressed as a strongly complementary potential for smoothly executing technology transfer, especially in the production and quality improvement segments. It originates from the inherent nature of the Vietnamese village tradition and several traditional principles for the organization of rural Vietnam (Tran, 1996; Tran, 1999).

The Japanese perspective strongly emphasizes a collectivistic orientation, which portends well for integrating into the Vietnamese community perspective to create a dynamic working environment for successful technology 
transfer. This derives from traditional Japanese society, which defines its collectivism into the two aspects of amae and wa (Herbig, 1995); amae is a key concept for understanding a social structure, where basic human behavior assumes and depends upon benevolence developed in childhood and continued throughout a person's life (Davies \& Ikeno, 2002; Jun \& Muto, 1995). It implies connectedness, collective interrelationship, vertical relationship, and group orientation (Herbig, 1995).

\subsubsection{Reward and Incentives}

The Vietnamese perspective on incentives that focuses on discovering the full benefit of individual skills through rewards was emphasized as one of the potential advantages for training technology and quality improvement, as long as managers execute flexible support. The traditional values of Vietnamese culture were influenced by Confucian thought and Buddhist enlightenment, which, when interwoven, result in an emphasis on the central virtues of an individual's intellectual and personal character (Pham, Vu, \& Tran, 2001). This creates a strongly built community relationship, with high ethnic self-esteem and a tradition of being eager to learn and be diligent, as well as having a creative attitude when dealing with any circumstance. Social values tend to promote wisdom and high education through contests, resulting in a sense of respect for honor and rewards for talent (Tran, 1999). These cultural values help Japanese companies easily initiate and conduct training programs in Vietnam when they have the proper managerial commitment and support.

\subsubsection{Harmony}

The Vietnamese management perspective concentrates on an affectionate lifestyle, harmonious living, and democratic behavior, which leads to respect for the community and the group. They expose positive and outgoing characters, which create democratic perspectives in the organization and cooperation among partners while learning technical and social knowledge and languages during technology transfer. As part of their human development while dealing with the natural environment and depending to such a great extent on nature, the Vietnamese have a true sense of respect and a desire to live harmoniously (Tran, 1996). Synthetic thinking has gradually formed and been accompanied by dialectical thinking: agricultural people are concerned not only with individual elements but also the interaction between them (Tran, 1999). Therefore, in terms of community organization, Vietnamese people usually live according to the principles of affection, leading to attitudes of righteousness and cultural respect (Tran, 1996).

Likewise, the core principle of the Japanese management style is Wa, harmony, emphasizing group harmony, peace, trust, sensitivity, and social cohesion (Herbig, 1995). The Wa lifestyle is affected by the wet-rice growing culture, where the cooperation of the village and neighbors is necessary for transplanting and harvesting (Herbig \& Jacobs, 1998). Given their harmonious working atmosphere, staff is genuinely concerned about the technology transfer value created and productivity sustained. Thus, for Japanese managers, managing groups and harmonious human relationships is more important than the tasks. This aspect is consistent with the synthetic view of social interactions in the working practices of Vietnamese managers. Therefore, their similar perspectives on harmony enable the Japanese and Vietnamese to easily create a sense of empathy, mutual understanding, and sharing, ensuring the success of their technology transfer.

\subsection{Power Distance (PDI)}

\subsubsection{Participating in Decisions}

Japanese managers believe that communicating and consulting with subordinates to obtain a consensus and enable employee involvement and participation in decision making are the key points for organizational success. This perspective makes the Vietnamese workers feel that their opinions are respected and their contributions to the workplace recognized. Employees can interact frequently, learn actively, practice their companies' respective technologies, look for holes in quality practices, hone the firm's production operations, and strive for and attain positive firm results. Vietnamese managers are likely to exhibit their executive power by imposing ideas on others. Although this influences technical sharing, communication, and information feedback for continuous improvement during a technology transfer, it also demonstrates the potential for such processes as setting rules, models, quality practice standards, work rituals, and training procedures in the early stage of the technology transfer. This perspective is particularly advantageous for technology transfer performance, since it ties it to managerial commitment and support for subordinates.

\subsubsection{Accessing Superior Managers}

Japanese group managers and their employees work within a unified harmony and maintain the tradition of a close family style, whether good or bad. This originates in Confucian theory, whereby a benevolent man who helps others establish what he himself wishes to establish helps others achieve something he wishes to achieve 
(Pham, Vu, \& Tran, 2001). In Japanese business strategy, the promotion of an enterprise manager to a higher level is often based on standards, such as how many capable staff members the director has trained. These factors help Vietnamese staff easily access and work together with Japanese managers, and also motivate the Vietnamese learning spirit and inspire them to make great efforts to train newcomers.

\subsubsection{Openness}

One characteristic of Japanese culture is high information density and continuous information flow (Pham, Vu, \& Tran, 2001; Nguyen, 2011). As much information as possible is dispensed to company staff to help them share knowledge, work together, and achieve unified goals. Japanese managers open offices at plants where hundreds of employees are willing and able to work together and take various opportunities to communicate, exchange information and experiments while implementing technology transfer and improving the transferred technology with co-workers on a daily basis.

\subsubsection{Hierarchy}

According to Hofstede, the PDI index of Vietnam and Japan is 70 and 54 respectively. Both countries are said to have high power distance, which means that people are willing to understand and accept the hierarchical arrangement of the system. The Vietnamese perspective reflects heavily on the natural hierarchy of role inequality and subordinates who expect to be directed by authority. It originates from emphasizing the differences in the view of autonomy that incorporates the patriarchal and hierarchical mind to create a perspective on imposing ideas on others (Tran, 1996). Another characteristic that derives from autonomous villages is that of showing power through independent capacity-self-support. Therefore, Vietnamese workers have a tradition of working hard and are eager to learn new technical knowledge through training programs in order to fulfill their own working requirements for further promotion. Japanese managers easily set up rules, control programs for quality practices, and maintain the responsibility for their subordinates' expectations.

\subsection{Masculinity (MAS)}

The management perspective compatibilities according to the MAS dimension were found to be strongest in two of the features of the attitude to work and human resource development.

The Japanese perspective on work focuses on a decisive and assertive character that gains competition and achieves performance. Subordinates are given clear instructions that are not intermingled with other matters. These traits can be traced to the samurai, where masculinity, assertiveness, honor, and ambition are emphasized (Herbig, 1995). These strong, masculine perspectives are evident in the extensive Japanese emphasis on training programs for human resource development, quality practices leading to a perfect product, and a strong managerial commitment to technology transfer objectives and business goals. They believe that, through long hours of training under strict supervision, workers can practice their skills and produce products with a minimum of error, which results in enhanced technology transfer performance and a sense of mutual trust in the team and their organization.

The Vietnamese management style values a sound quality of life, modest expectations, and interpersonal relationships. Vietnam, with its agricultural lifestyle and dialectical thinking, has formed positive and negative principles, flexible adaptability, dual behavior, great optimism, and confidence in the future (Tran, 1996; Pham, $\mathrm{Vu}, \&$ Tran, 2001). The Vietnamese demonstrate a consensus for long-term human relationship development, assisting Japanese subsidiaries in their continued effort to achieve productivity and support the established technology transfer business in Vietnam.

\subsection{Uncertainty Avoidance (UAI)}

The compatibilities in this dimension lie mainly in Vietnamese adventurousness and Japanese production control that integrate well with other cultural dimensions of both partners.

First, the Vietnamese perspective is always adaptable, willing to take a chance at approaching new problems or new corporate cultures, and open to risk. They enjoy novel events, different values, taking risks, and accept uncertainty as an aspect of everyday life. Indeed, the synthetic and dialectical thinking, combined with the affectionate principles of the Vietnamese people lead to flexibility and a conciliatory attitude (Tran, 1996; Tran, 1999). These views suggest the disadvantages inherent in their quality control, production control, and in the total value chain of the technology transfer process (Nguyen, Takanashi, \& Aoyama, 2012). At the same time, the potential advantages emanating from these characteristics include the ability to adequately execute quality improvement, training programs, and communication, and to create a sound hybrid corporate culture.

Japanese culture also encourages stability, commitment, and a sense of belonging to the corporation. Japanese 
companies use the loyalty and enthusiasm of employees, committed to a long-term working relationship with a firm, to bolster and stabilize themselve. Therefore, the Japanese management style is more conscientious about risk and chance. They make decisions after examining the relevant factors from the perspective of both the internal and external working environments. Japanese managers pay more attention to planning for the business, maintaining the machinery, controlling product quality, correctly protecting delivery time, and training. Although these "cautious" attributes can suppress individual creativity, the Japanese quickly commit to long-term development, the establishment of technology transfer projects in their early stages, and interactions for mutual understanding.

\subsection{Long-Term Orientation (LTO)}

The discovered compatibilities belonging to this dimension mainly lie in the Japanese aspects that integrate well with other Vietnamese cultural dimension.

The Japanese, emboldened with the samurai spirit, have exploited the positive points of the benevolence and gentleman doctrines of Confucius to promote human factors (Pham, Vu, \& Tran, 2001). Thus, in pursuing strategic objectives, Japanese managers focus on two elements of men and management to create long-term competitive advantages for the transferred technology. The managers must create value to promote a vigorous work spirit and encourage creativity in hundreds of people's technology transfer practices. They pay particular attention to developing, managing human relationship, making business plans, taking care of products, and production process. Moreover, dynamic strategies such as managerial commitment, frequent communication, and training are necessary for setting company objectives.

Briefly, then, we could conclude that most of the intercultural similarities and complementary potential lie within the Collectivism and Power Distance dimensions deriving from two contradictory characteristics of Vietnamese culture-its community spirit and autonomy.

\section{Analytical Result-2: Actual Hybrid Managerial Practices for Cross-Cultural Technology Transfer}

Considering the above analysis and interviews, the practical hybrid solutions that are especially important to technology transfer-frequent interaction (INT), training (TRA), team-based work (TEA), quality practice (QUA), and managerial commitment and support (COM) - can effectively exploit the similarities and complementary potential of the Vietnamese and Japanese cultures in management practices (see Table 1). Figure 2 provides a general view of the intercultural advantages that can synergize and how to synergize for efficient technology transfer. The next paragraphs discuss the formation of hybrid practices and why the hybridizing of intercultural potential in management practices can promote effective technology transfer performance in the context of cultural differences.

Table 1. The similarities/compatibilities and actual hybrid practices of Hofstede's dimensions

\begin{tabular}{|c|c|c|c|c|c|c|}
\hline $\begin{array}{l}\text { Cultural } \\
\text { dimension-Category }\end{array}$ & $\begin{array}{l}\text { The similarities/compatibilities in management } \\
\text { perspectives based on national culture }\end{array}$ & INT & TRA & TEA & QUA & $\mathrm{COM}$ \\
\hline IDV-Team spirit & $\begin{array}{l}\text { Collectivistic orientation, various modes of } \\
\text { cooperation and strong solidarity. }\end{array}$ & & & V-J & V-J & \\
\hline IDV- Rewards/incentives & $\begin{array}{l}\text { - Discover full benefit of individual skills through } \\
\text { rewards. }\end{array}$ & & $\mathrm{V}$ & & $\mathrm{V}$ & $\mathrm{V}$ \\
\hline \multirow[t]{3}{*}{ IDV-Harmony } & $\begin{array}{l}\text { - Sense of respect for community, group, and core } \\
\text { concepts of peace and harmony. }\end{array}$ & V-J & & V-J & & \\
\hline & - Democracy and equality in organization & & & V-J & & \\
\hline & $\begin{array}{l}\text { - Affectionate lifestyle, desire to live harmoniously, and } \\
\text { harmonious human relationships. }\end{array}$ & V-J & & & & \\
\hline \multirow[t]{2}{*}{$\begin{array}{l}\text { PDI-Participation in } \\
\text { decisions }\end{array}$} & $\begin{array}{l}\text { - Exhibit power in executive management by imposing } \\
\text { ideas on others and self-support. }\end{array}$ & & V & & $\mathrm{V}$ & $\mathrm{V}$ \\
\hline & $\begin{array}{l}\text { - Communicate with and consult subordinates to obtain } \\
\text { a consensus, and enable employee involvement in } \\
\text { decision making. }\end{array}$ & $\mathrm{J}$ & $\mathrm{J}$ & $\mathrm{J}$ & $\mathrm{J}$ & \\
\hline $\begin{array}{l}\text { PDI-manager's } \\
\text { accessibility }\end{array}$ & $\begin{array}{l}\text { - Group management and other employees work in } \\
\text { unified harmony and maintain traditional, close family }\end{array}$ & $\mathrm{J}$ & $\mathrm{J}$ & $\mathrm{J}$ & & \\
\hline
\end{tabular}


PDI- Openness

PDI- Hierarchy

MAS-Attitude toward work

MAS- Human resource development

UAI- Production control

UAI-Adventurous-ness

LTO- Strategic objective style, whether the situation is good or bad.

- Continuous information flow, disclosure of information possible, sharing the knowledge and work together.

- Heavily reflecting the natural hierarchy of inequality, understanding and accepting the hierarchical arrangement in the system, and expecting to be directed by authority.

- Expect to become modest and interested in $\mathrm{V}$ relationships.

- Expect to be decisive and assertive with competition and performance achievements.

- Work for quality of life.

- Give instructions to subordinates clearly, do not mix with other matters.

V-J V-J V-J

- Extensive training for long hours under strict supervision.

- Protect delivery time.

- Understand the meaning of time for every activity.

- Pay more attention to preventive maintenance of machinery.

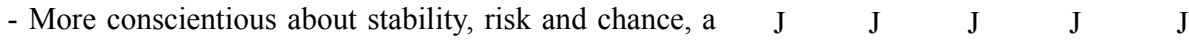
sense of corporation.

- Eager to take a chance of approaching new problems. $\quad \mathrm{V} \quad \mathrm{V} \quad \mathrm{V}$

- Pay attention to developing business plans.

- Take care of product and production process.

- Develop and manage human relationships.

- Pay attention to company's motto.

J $\quad \mathrm{J} \quad \mathrm{J}$

V

$\begin{array}{lllll} & \mathrm{J} & & \mathrm{J} & \mathrm{J} \\ \mathrm{J} & \mathrm{J} & \mathrm{J} & \mathrm{J} & \mathrm{J} \\ & \mathrm{J} & & \mathrm{J} & \mathrm{J}\end{array}$

$\mathrm{J} \quad \mathrm{J} \quad \mathrm{J}$

$\mathrm{J}$

$\mathrm{J} \quad \mathrm{J}$

Note V: Vietnamese management practices. J: Japanese management practices

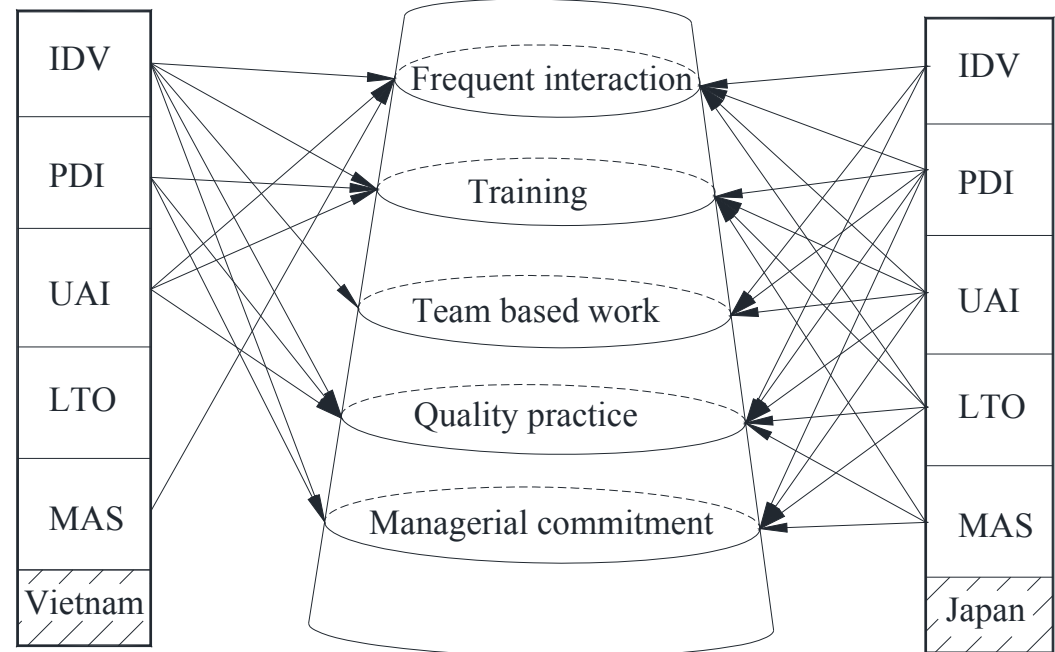

Figure 2. The hybrid managerial practices of intercultural potential for efficient technology transfer 


\subsection{Frequent Interaction (INT)}

The interviewees believe that, to optimally utilize the cultural potential of each country and quickly achieve a successful cross-cultural technology transfer program, interactive activities should be considered frequently.

The hybrid solution aimed at frequent interaction is strongly supported by the management perspectives of the Vietnamese style, given its harmony (IDV), attitude toward work (MAS), and adventurousness (UAI); and of the Japanese style, with its harmony (IDV), participation in decisions (PDI), manager's accessibility (PDI), openness (PDI), production control (UAI), and strategic objective (LTO), as well (seeTable 1).

First, the notions of harmony, community, group, and peace shared by both the Japanese and the Vietnamese perspectives are the foundation for frequent interaction solutions. Thus, they help to easily cooperate, engage with each other, and create affective-based closeness, which all capture a sense of togetherness, sympathy, mutual understanding, mutual trust, and sharing.

Second, the Vietnamese, with their willingness to seize an opportunity, eagerness to work with their Japanese counterparts to learn the new culture (both technically and socially) and establish social relationships both facilitate and augment their respective opportunities for success. They also expect to become modest, work for life quality, and are interested in relationships. Coupled with their similarities to Vietnam, Japan has the inherent attributes of unifying harmony and maintaining a traditional, close family style, whether the situation is good or bad; they also value the disclosure of all possible information, consensus in decision making, and sharing knowledge with employees to facilitate working together.

Third, the other factors in Japanese strategic objectives' frequent interaction are sharing the meaning of every activity, displaying the motto of the company in a positive way, taking care of the products and process, and developing and managing human relationships into valuable assets.

Therefore, frequent interaction promotes exchanges, and communication promotes extensive intercultural coordination, learning about one another, sharing knowledge, and allows for efficient technology transfers to be quickly implemented.

\subsection{Training (TRA)}

The hybrid solution using training synergies relevant to the Vietnamese perspective-rewards and incentives (IDV), participation in decisions (PDI), hierarchy (PDI), and adventurousness (UAI) - acts upon the Japanese management style - participation in decisions (PDI), manager's accessibility (PDI), openness (PDI), hierarchy (PDI), human resource development (MAS), production control (UAI), and strategic objective (LTO)—(see Table 1). From these perspectives, the Japanese train with the goal of attaining long-term opportunities with the transferred technology. Protecting delivery time, providing the meaning of time for every activity, practicing preventive machinery maintenance, and disclosing information to employees in a positive way all facilitate the training solution. Meanwhile, the Vietnamese have the intrinsic attributes of an eagerness to take chances and gain new knowledge and a willingness to take the effort to discover the full benefit of individual skills for rewards. These attributes help companies easily run their training programs appropriately. Also, by training using the appropriate methods, partners have the opportunity for face-to-face communication, where they can interact with each other using a language and symbols they both understand, which ultimately increases mutual trust, the effective use of technology, and the technology transfer process.

\subsection{Team-Based Work}

Hybridizing as team-based work utilizes the potential advantages of both the Japanese and Vietnamese management styles in their team spirit (IDV) and harmony (IDV) cultural dimensions and from the participation in decisions (PDI), manager's accessibility (PDI), openness (PDI), and production control (UAI) aspects of the Japanese management style (see Table 1). Its characteristics enable workers to engage in collective acts, unite, help one another, think about each other, consider others as part of the family, elicit respect for the community and group, and create a democratic organizational life. Team-based work sustains the well-known Ringi system-a unique way of coming to a consensus about new ideas, based on consultations among managers from different levels about new ideas and/or projects (Davies \& Ikeno, 2002)-that attains consensus in decision making. Simultaneously, it evokes the solidarity spirit, one of the main goals of the Vietnamese community. Therefore, Japanese and Vietnamese managers strongly believe that team-based organization holds an integral intercultural potential as a management practice to produce efficient technology transfer. Through this, every team member has a chance to collaboratively work on tasks, engage in mutual self-help, and merge individual efforts within the group context to achieve positive results. The overall process of technology transfer is thus refined. 


\subsection{Quality Practice}

Vietnamese and Japanese managers emphasized that, in proceeding with international technology transfer, practicing quality is a fundamental way to integrate the cultural potential of each partner, maximize cultural synergy, and lead people to mutual trust, understanding, and sharing.

The hybrid solution focuses on quality practices to integrate the potential advantages of the team spirit (IDV), rewards and incentives (IDV), participation in decisions (PDI), hierarchy (PDI), and adventurousness (UAI) aspects of the Vietnamese management styles and the participation in decisions (PDI), openness (PDI), hierarchy (PDI), attitude toward work (MAS), production control (UAI), and strategic objective (LTO) aspects of the Japanese management styles (see Table 1).

First, Japanese strategic objectives pay attention to making business plans, taking care of products and production processes, and displaying the motto of the company in a positive way as fundamental to quality practice solutions. Likewise, the high uncertainty views of Japanese culture as displayed in actions such as protecting delivery times, the meaning of time for every activity, and paying more attention to the preventive maintenance of machinery strengthens quality practices.

Second, another supportive Japanese attitude toward work is the expectation to be decisive and assertive toward its competition and performance. It favors achieving quality practice by clearly explaining instructions to subordinates and sharing information with employees to help them work together easily. It also obtains a consensus and enables employee involvement in decision making, which helps expand quality practice within the company.

Third, coupled with the Japanese practices, the Vietnamese management perspectives-exhibiting power in executive management by imposing ideas on others and independent capacity/self-support- help to set the rules, standards, and qualifications for quality control. The wish to discover the full value of individual skills through rewards makes quality practice solutions run well, by motivating the search for the most appropriate method of quality improvement. Therefore, quality practices incentivize people to strive for and maintain mutual trust, understanding, and sharing in a way that facilitates an effective technology transfer.

\subsection{Managerial Commitment and Support}

The hybrid solution aimed at managerial commitment and support integrates the cultural potential of the rewards and incentives (IDV), participation in decisions (PDI) and hierarchy (PDI) aspects of the Vietnamese management perspective and the hierarchy (PDI), production control (UAI), strategic objective (LTO), and attitude toward work (MAS) aspects of the Japanese management style (see Table 1). By practicing this solution, the Vietnamese perspective of exhibiting power in executive management by imposing ideas on others and focusing on independent self-support is activated as their potential strength. At the same time, the aspects of Japanese management style that aim for a long-term strategic objective strategy-disclosing the annual plan, using the motto of the company in a positive way, being careful with the product/production elements, striving for safety over profit, and developing and managing human relationships-are the underlying solutions for managerial commitment and support. The other Japanese management perspectives are also displayed in such actions as closely monitoring delivery times, the importance of time for every activity, paying more attention to the preventive maintenance of machinery, and sustaining the hybrid solution. Likewise, the Japanese attitude to strengthening the work environment helps implement the hybrid solution for managerial commitment and support, which is expected to be decisive and assertive with competitive advantages and high achievement.

Accordingly, the technology transfer process requires the acquisition of new technical knowledge, new techniques, and even a new way of thinking and new, innovative ideas. Thus, there must be continuous managerial commitment, support, and evaluation to achieve effective long-term technology transfer performance.

Overall, we argue that, even though the combinable potentials are few, the Japanese subsidiaries will be more successful if they address the organic solutions for inducing employees' cultural beliefs.

\section{Proposing the Systematic Framework of Hybrid Managerial Practices for Efficient Technology Transfer}

On the analytical results in section 5 and section 6 , this section proposes a systematic view on the foundation of and discusses the meaning of cultural hybrid practices in achieving the efficiency of cross-cultural technology transfer.

\subsection{Framework}

This systematic framework proceeds through the three steps below (see Figure 3). 
Step 1: Determine the cultural potential in the management practices of each country

The first task is to identify the similarities and compatibilities or differences that represent a combinable potential for the management perspectives, based on the cultures of the home and host country's corporations. The identifying process should refer to Hofstede's cultural dimensions. This is an essential foundation for exploring the successful strategic solutions for technology transfer performance. This step activates the questioning of which intercultural management practices can synergize and how to deal with intercultural challenges in positive ways to turn cultural potential into advantages for efficiently achieving technology transfer performance and long-term competition.

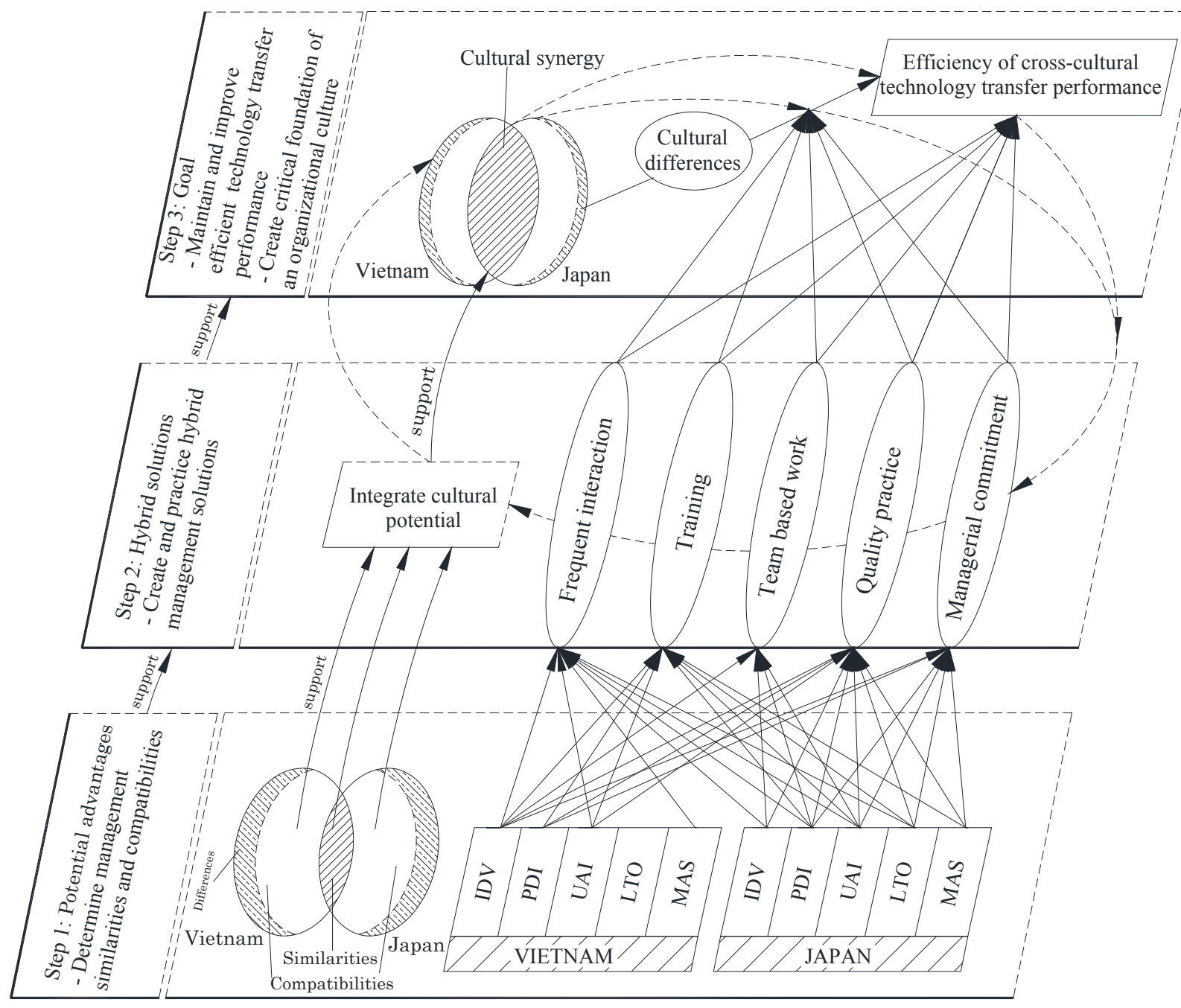

Figure 3. The systematic framework of hybrid managerial practices for efficient technology transfer

Step 2: Create and practice the hybrid management solutions

The second task is to search for hybrid solutions that integrate the identified cultural potential in a systematic and synergistic way. We suggest that the hybrid solutions should focus on activating the behavior of local workers and addressing the mindset of the home and host managers and workers. Abo's theoretical framework for management systems at hybrid factories should serve as a reference for determining the hybrid practicing strategies. Essentially, five hybrid solutions are considered critical for achieving effective cross-cultural technology transfer performance in Japanese subsidiaries in Vietnam: frequent interaction, training, team based work, quality practice, and managerial commitment and support. Seeking and practicing solutions that combine intercultural core competence in management perspectives provides a strong foundation for creating intercultural synergy in the next step. The process of creating and applying the strategic solutions should be done by both international and local managers to facilitate the progress of intercultural convergences and smooth technology transfer. 
Step 3: Maintain and improve the achieved technology transfer performance

In this step, both managers have experience in successfully implementing technology transfer performance under the context of cultural differences. Basically, as the cultural synergy is achieved, the impact of cultural differences on technology transfer performance simultaneously decreases, and technology transfer performance is successfully achieved. To accomplish efficient performance, the hybrid solutions should be maintained and continuously improved through upgraded practical techniques.

\subsection{Discussion}

First, hybrid managerial practices reveal their impact in two ways, by (1) activating the local staff's behavior through on-the-job training, team based work, quality practice, and managerial commitment and support and (2) critically addressing the mindset of the home and host managers and workers by training (including social knowledge and languages training) and frequent interaction. In the short term, we argue that the stronger is the cultural hybridization effort, the higher the probability of a positive technology transfer outcome.

Second, the strategies of intercultural synergy aimed at efficient technology transfer relate to the progress of cultural learning and partner integration. Through the hybridizing of the intercultural potential during the technology transfer process, the new corporate culture progressively grows into an organization. In the long term, the graphical interpreting circle of Figure 3 shows that the more hybrid managerial practices are exercised, the more convergence of mutual cultures occurs, the more the impact of cultural differences in management perspectives on technology transfer performance decreases, and the more efficient the technology transfer becomes. Again, the better efficient technology transfer reaches, the more hybrid managerial practices are upgrated, and the more cultural synergy creates.

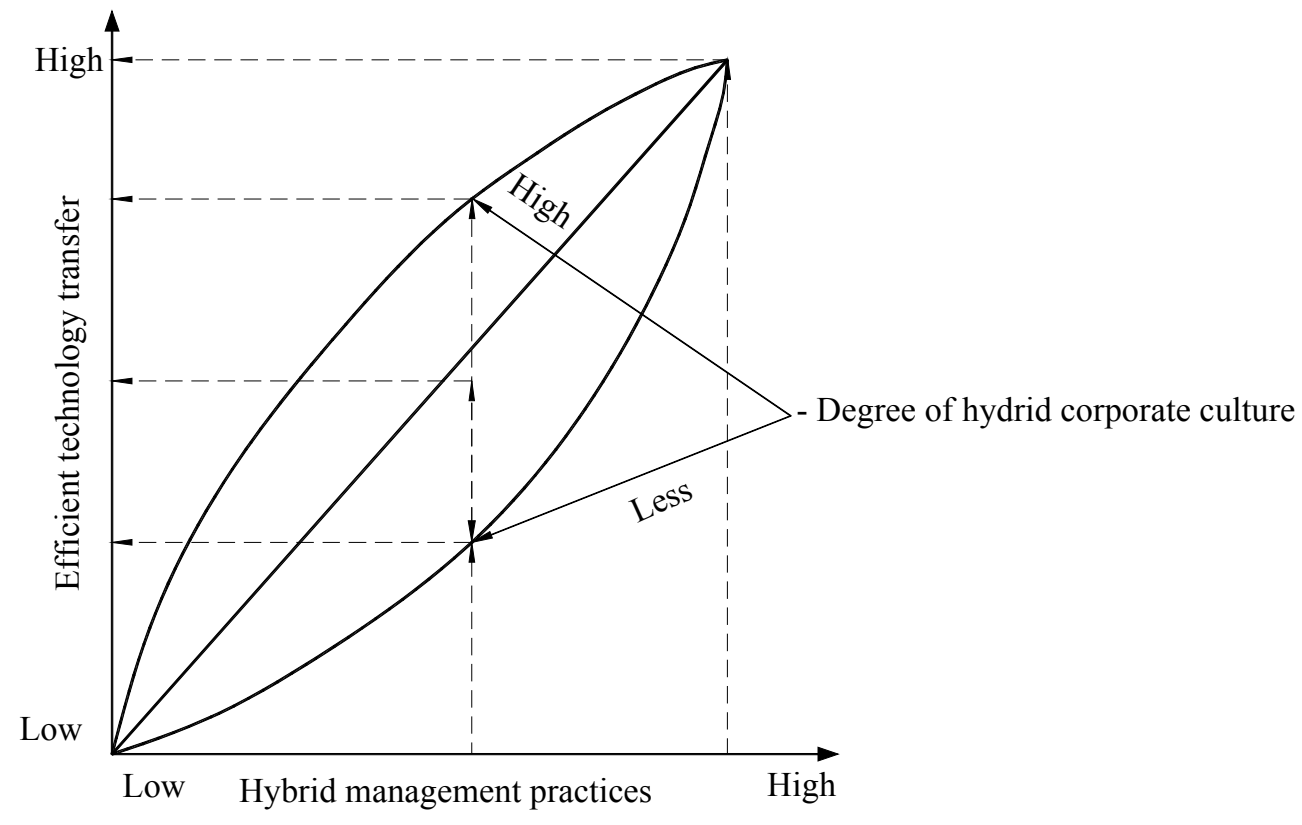

Figure 4. Assumption of hybrid managerial practices and efficient technology transfer

Third, we could suggest (whether the Japanese newcomers invest in Vietnam or overseas) that the more hybrid management is practiced, the more efficient the technology transfer becomes. Practicing managers should also consider that the above proportional relationship can be embedded up or down according to the degree of the hybrid corporate culture (see Figure 4).

\section{Conclusion}

This study has obtained productive insights from three significant discoveries: (1) the similarities and compatibilities between Japanese and Vietnamese management perspectives based on the national cultures of each country, considered as having the most relevant intercultural potential in technology transfer, can advantageously synergize; (2) the practical hybrid solutions that are especially important to technology transfer-frequent interaction, training, team based work, quality practice, and managerial commitment and support-can effectively integrate the cultural values, attributes, and beliefs of both Vietnamese and Japanese 
cultures in term of managerial practices. These essentially strategic actions directly activate the behavior of local workers, address the mindsets of Japanese managers and Vietnamese workers, and exploit the core cultural values of each country; and (3) the systematic framework works through three steps-determining combinable management perspectives based on each culture, creating and practicing hybrid managerial solutions, and maintaining and improving the achieved technology transfer performance-that positively address the directions for which intercultural advantages can synergize, how to synergize, and why the cultural synergy can promote efficient technology transfer in the context of cultural differences. As a result, we conclude that the hybridization of intercultural potential is not only the mixing of cultural management styles but can also be perceived as an intellectual strategy for exploiting home and host advantages in efficient technology transfer and as a critical foundation for the creation of an organizational culture.

Accordingly, we suggest five practical implications. (1) To thoughtfully develop a cross-cultural technology transfer approach efficiently, managers should learn the perspective of Hofstede's cultural dimension in order to obtain a fundamental cultural understanding, identify the positive aspects (the similarities), discover issues that may become a problem (the cultural differences) and that can reveal a combinable potential between the management perspectives of the host and home countries' practices (the compatibilities). (2) The international and local manager should participate in determining the strategic solutions needed to deal with any cultural challenges that may occur when implementing their technology transfer and use a positive approach to integrating their employees' cultural beliefs. (3) The combination of cultural potential is not the simple math of one plus one equals two but will be more and less than two depending on the vision, knowledge, and capability of the managers. With the thorough awareness of new and combinable potential, technology transfer managers can instantly improve the technology transfer activity of their respective organizations. Despite their few cultural similarities, Japanese subsidiaries will achieve prosperity and competitive advantages if they develop strategically organic solutions in consideration of Abo's management practices and promote the process of cultural convergence and overcome the cultural distance between the host and home countries' management perspectives. (4) In the long term, working on intercultural synergy solutions through technology transfer is the critical foundation of building an organizational culture that directly influences the behavior, interactive relationships, and cultural beliefs of employees and the long-term cooperation and competition of Japanese subsidiaries overseas, especially in Vietnam. (5) The results and approach of this study can be generalized to apply to other countries in which Japanese companies are attempting to enlarge their manufacturing network as well as to Vietnamese partners wishing to create technological advantages by attracting direct foreign investment and strategic alliances.

In sum, this study integrates three fundamental theories-Hofstede's cultural theory, Adler's intercultural synergy, and Abo's management practices - to address important issues that have yet to be sufficiently conceptualized in cross-cultural technology transfer research: (1) the cultural aspects of Vietnamese and Japanese management practices that are potential advantages in implementing technology transfer and can be synergized properly, as hinted by Nguyen, Takanashi, \& Aoyama (2012); (2) the significant managerial activities that utilize cultural potential, convert it into advantages, and minimize the impact of cultural differences on technology transfer performance through; and (3) why synergizing cultural potential can promote cross-cultural technology transfer performance. Correspondingly, this study also captures the notion of Trompenaars \& Hampden-Turner (1998) by investigating the similarities and combinable potential among intercultural management practices.

Given the results of this study, we propose three important issues for future research.

First, despite attempting to utilize Hofstede's (2010) cultural lens in exploring the similarities and compatibilities between Japanese and Vietnamese management practices during technology transfer, the analysis is limited to the five primary cultural dimensions disclosing the behaviors and attitudes of employees and managers. Therefore, the proposed framework for hybrid solutions using intercultural potential for efficient cross-cultural technology transfer will become optimal only if Hofstede's remaining cultural features are examined. Additionally, other aspects could be considered, for example intellectual autonomy, affective autonomy, conservatism, assertiveness, performance orientation, future orientation, and human orientation (Schwartz, 1999; Matsumoto \& Yoo, 2006). Asserting a practical component, managers and researchers can decide which elements are valuable.

Second, the practical hybrid solutions using intercultural potential showed their importance to technology transfer. They are a part of Abo's (1994) management system relating to internal work organization and administration at hybrid factories. Further research could extend the investigation into the supplementary cultural aspects mentioned above, connecting the collected data with Adler's (2008) intercultural synergy and other 
Abo's (1994) management practices, for example hiring policy, job security, labor unions, grievance procedures, and parent-subsidiary relations.

Third, through the strength of the qualitative approach, the findings in this study may condition the directions of empirical studies in cross-cultural technology transfer research. Issues worthy of examination include: (1) the practical management factors that efficiently promote international technology transfer; (2) the elements of the Japanese management style that should be adjusted to integrate with the Vietnamese culture; (3) the effects of technology transfer on the formation of Vietnamese management styles; (4) the role of organizational culture in technology transfer performance; and (5) a firm's business performance in term of productivity and innovation capacity. The statistical evidence will be particularly significant, academically and practically, as proof of whether (1) the Japanese newcomers invest in Vietnam or overseas, given the proportional relationship, increased hybrid managerial practices make technology transfer performance more efficient, and whether (2) the above relationship is embedded up or down according to the degree of the hybrid corporate culture.

This study serves to integrate the core values of the hybridizing perspective in the literature of cross cultural management into the issue of cross-cultural technology transfer that the prevailing research has not yet adequately addressed.

\section{Acknowledgements}

We are indebted to the Ritsumeikan Kokusaiteki Research Fund and the Japanese Ministry of Education, Science, and Culture for their generous Grant in Aid for International Research Activities. We gratefully acknowledge the Japanese directors and Vietnamese production managers working at Japanese subsidiaries in Vietnam for their strong support during intensive discussions. Additionally, the earlier draft were read and commented on by Prof. Eugene Choi and Prof. Chikako Takanashi, who are gratefully thanked.

\section{References}

Abo, T. (1994). Hybrid factory: the Japanese production system in the United States. New York: Oxford University Press.

Adler, N. J., \& Gundersen, A. (2008). International dimensions of organizational behavior (5th ed.). Mason: South-Western.

Ando, T., Kawashima, M., \& Kan, K. (2005). Chugoku no gijutsu hatten to gijutsu iten: riron to jisshou [Technology development and technology transfer in China: Theoretical and empirical analysis]. Kyoto: Minerva Shobo.

Bhagat, R. S., Kedia, B. L., Harveston, P. D., \& Triandis, H. C. (2002). Cultural variations in the cross-border transfer of organizational knowledge: An integrative framework. The Academy of Management Review, 27(2), 204-221.

Blaxter, L., Hughes, C., \& Tight, M. (2010). How to research (4th ed.). Maidenhead, England: McGraw-Hill.

Bozeman, B. (2000). Technology transfer and public policy: A review of research and theory. Research Policy, 29, 627-655. http://dx.doi.org/10.1016/S0048-7333(99)00093-1

Buckley, P. J., \& Casson, M. C. (1998). Models of multinational enterprise. Journal of International Business Studies, 29(1), 21-44. http://dx.doi.org/10.1057/palgrave.jibs.8490023

Chen, J., Sun, P., \& McQueen, R. (2010). The impact of national cultures on structured knowledge transfer. Journal of Knowledge Management, 14(2), 228-242. http://dx.doi.org/10.1108/13673271011032373

Creswell, J. W. (2009). Research design: qualitative, quantitative and mixed methods approaches (3rd ed.). Los Angeles: Sage Publications.

Davenport, T. H., \& Prusak, L. (2000). Working knowledge: how organizations manage what they know. Boston: Harvard Business School Press.

Davies, R. J., \& Ikeno, O. (2002). The Japanese mind: understanding contemporary Japanese culture. Tokyo: Tuttle Publishing.

Derakhshani, S. (1984). Factors affecting success in international transfers of technology: A synthesis, and a test of a new contingency model. Developing Economies, 22(1), $27-46$. http://dx.doi.org/10.1111/j.1746-1049.1984.tb00650.x

Dey, I. (1993). Qualitative data analysis: A user-friendly guide for social scientists. London: Routlege. http://dx.doi.org/10.4324/9780203412497 
Fuller, E. V. (2009). Going global: culture, gender, and authority in the Japanese subsidiary of an American corporation. Philadelphia: Temple University Press.

Goulding, C. (2002). Grounded theory: A practical guide for management, business and market researchers. London: Sage Publications Ltd.

Hedges, A. (1985). Group interviewing. In R. Walker (Ed.), Applied qualitative research. Aldershot, UK: Gower Publishing.

Herbig, P. (1995). Innovation Japanese style: a cultural and historical perspective. Westport, Conn.: Quorum Books.

Herbig, P., \& Jacobs, L. (1998). Culture as an explanatory variable for the Japanese innovative processes. Cross cultural management, 5(3), 5-30. http://dx.doi.org/10.1108/13527609810796808

Hofstede, G., Hofstede, G. J., \& Minkov, M. (2010). Cultures and organizations: Software of the mind: Intercultural cooperation and its importance of survival (3rd ed.). New York: McGraw-Hill.

Holden, N. (2002). Cross-cultural management: A knowledge management perspective. Harlow: Financial Times Prentice Hall.

Jones, M., \& Alony, I. (2007). The cultural impact of Information systems- through the eyes of Hofstede- a critical journey. Issues in Informing Science and Information Technology, 4, 407-419.

Jun, J. S., \& Muto, H. (1995). The hidden dimension of Japanese administration: Culture and its impact. Public Administration Review, 55(2), 125-134. http://dx.doi.org/10.2307/977178

Le, N. H., \& Evangelista, F. (2007). Acquiring tacit and explicit marketing knowledge from foreign partners in IJVs. Journal of Business Research, 60, 1152-1165. http://dx.doi.org/10.1016/j.jbusres.2007.04.006

Leung, K., Bhagat, R., Buchan, N. R., Erez, M., \& Gibson C. B. (2011). Beyond national culture and culture-centricism: A reply to Gould and Grein (2009). Journal International Business Studies, 42(1), 177-181. http://dx.doi.org/10.1057/jibs.2010.38

Lin, B. W., \& Berg, D. (2001). Effects of cultural difference on technology transfer projects: An empirical study of Taiwanese manufacturing companies. International Journal of Project Management, 19, 287-293. http://dx.doi.org/10.1016/S0263-7863(99)00081-2

Lin, W. B. (2007). Factors affecting the correlation between interactive mechanisms of strategic alliance and technological knowledge transfer performance. The Journal of High Technology Management Research, 17, 139-155. http://dx.doi.org/10.1016/j.hitech.2006.11.003

Lucas, L. M. (2006). The role of culture on knowledge transfer: The case of the multinational corporation. The Learning Organization, 13(2-3), 257-275. http://dx.doi.org/10.1108/09696470610661117

Lyles, M. A., \& Salk, J. E. (1996). Knowledge acquisition from foreign parents in international joint ventures: An empirical examination in the Hungarian context. Journal of International Business Studies, 27(5), 877-903. http://dx.doi.org/10.1057/palgrave.jibs.8490155

Mansfield, E., Romeo, A., Schwarts, M., Teede, D., Wagner, S., \& Brach, P. (1982). Technology transfer, productivity, and economic policy (1st ed.). New York: W W Norton \& Co Inc.

Matsumoto, D., \& Yoo, S. H. (2006). Toward a new generation of cross cultural research. Association for Psychological Science, 1(3), 234-250. http://dx.doi.org/10.1111/j.1745-6916.2006.00014.x

Michael, J., \& College, W. (1997). A conceptual framework for aligning managerial behaviors with cultural work values. International Journal of Commerce \& Management, 7(3-4), 81-101. http://dx.doi.org/10.1108/eb047357

Mowery, D. C., Oxley, J. E., \& Silverman, B. S. (1996). Strategic alliances and inter-firm knowledge transfer. Strategic Management Journal, 17(Winter Special Issue), 77-91.

Nasif, E. G., Al-Daeaj, H., Ebrahimi, B., \& Thibudeaux, M. S. (1991). Methodological problems in cross-cultural research: an updated review. Management International Review, 31(1), 79-91.

Nguyen, T. D. N., Takanashi, C., \& Aoyama, A. (2012). Can Efficient Technology Transfer Be Achieved Through A Hybrid Corporate Culture? A study on Japanese Manufacturing Subsidiaries in Vietnam. International Journal of Business and Management, 7(7), 24-39.

Nguyen, T. T. (2011). Van hoa Nhat ban [Japanese cultures]. Ho Chi Minh city: Culture Information 
Publication.

Pak, Y., \& Park, Y. (2004). A framework of knowledge transfer in cross-border joint ventures: An empirical test of the Korean context. Management International Review, 44(4), 435-455.

Patton, M. Q. (2002). Qualitative evaluation and research methods (3rd ed.). Thousand Oaks, California: Sage Publications.

Pauleen, D. J., Wu, L. L., \& Dexter, S. (2007). Exploring the relationship between national and organizational culture, and knowledge management. In D. J. Pauleen (Ed.), Cross-cultural perspectives on knowledge management (pp. 3-19). London: Libraries Unlimited Press.

Pham, V. N., Vu, H., \& Tran, T. T. (2001). Van hoa trong kinh doanh [Culture in business]. Ho Chi Minh city: Labor Publication.

Ran, Z. (2008). "Dual different cultures" integration: An integration performance measuring model of corporate cross-border M \& A. International Journal of Business and Management, 3(3), 30-34.

Rebentisch, E. S., \& Ferretti, M. (1995). A knowledge asset-based view of technology transfer in international joint ventures. Journal of Engineering and Technology Management, 12, 1-25. http://dx.doi.org/10.1016/0923-4748(95)00002-4

Ross, D. N. (1999). Culture as a context for multinational business: a framework for assessing the strategy culture 'fit'. Multinational Business review, 7(1), 13-19.

Sazali, A. W., \& Raduan, C. R. (2011). The inter-firm technology transfer in Malaysia- A holistic approach. Saarbrucken: VDM Verlag Dr. Muller.

Sazali, A. W., Raduan, C. R., Jegak, U., \& Haslinda, A. (2009). Effects of inter-firm technology transfer characteristics on degree of inter-firm technology transfer in international joint ventures. European Journal of Scientific Research, 35(3), 474-491.

Schlunze, R. D., Hyttel-Srensen, J., \& Ji, W. (2011). Working towards hybrid solutions: The possibility of an IHRM model in Japan. Ritsumeikan Business Journal, 5, 99-118.

Schwartz, S. H. (1999). A theory of cultural values and some implications for work. Applied Psychology: An International Review, 48(1), 23-47. http://dx.doi.org/10.1111/j.1464-0597.1999.tb00047.x

Simonin, B. L. (1999). Ambiguity and the process of knowledge transfer in strategic alliances. Strategic $\begin{array}{lll}\text { Management Journal, } & \text { 20(7), } & 595-623\end{array}$ http://dx.doi.org/10.1002/(SICI)1097-0266(199907)20:7<595::AID-SMJ47>3.0.CO;2-5

Tran, N. T. (1996). Tim ve ban sac van hoa Vietnam: cai nhin he thong-loai hinh [Discovering the identity of Vietnamese culture: Typological-systematic views]. Ho Chi Minh city: Ho Chi Minh Publication.

Tran, N. T. (1999). Co so van hoa Vietnam [Vietnam's fundamental culture]. Ho Chi Minh city: Education Publication.

Trompenaars, A., \& Hampden-Turner, C. (1998). Riding the waves of culture: understanding cultural diversity in global business (2nd ed.). New York: Mc Graw-Hill.

Tsang, E. (1998). Can guanxi be a source of sustained competitive advantage for doing business in China? The Academy of Management Executive, 12(2), 64-72. http://dx.doi.org/10.5465/AME.1998.650517

William, F., \& Gibson, D. V. (1990). Technology transfer: A communication perspective. Newbury Park, California: Sage Publications.

Yamashita, S. (1991). Transfer of Japanese technology and management to the ASEAN countries. Tokyo: University of Tokyo Press.

Yin, R. K. (2009). Case study research: Design and method (4th ed.). Thousand Oaks, California: Sage Publications.

\section{Note}

Please cite this article as: Nguyen, T. D. N., \& Aoyama, A. (2012). Does the Hybridizing of Intercultural Potential Facilitate Efficient Technology Transfer? An Empirical Study on Japanese Manufacturing Subsidiaries in Vietnam. Asian Social Science, 8(11), 26-43 